\title{
Social Support and Coping Styles in Predicting Suicide Probability among Turkish Adolescents ${ }^{\mathrm{i}}$
}

\author{
Fulya Cenkseven-Önder
}

Department of Psychological Counseling and Guidance, Faculty of Education, Cukurova University, Turkey

Copyright $\bigcirc 2018$ by authors, all rights reserved. Authors agree that this article remains permanently open access under the terms of the Creative Commons Attribution License 4.0 International License

\begin{abstract}
This study aims to investigate whether the perceived social support and coping styles are predictors of suicide probability by gender. The study was conducted with 445 high schools students, 227 girls, and 218 boys. The participants were aged between 14 and 18, and their average age was 15.90. Data were collected through the 'Multidimensional Scale of Perceived Social Support', the 'Ways of Coping Questionnaire', and the 'Suicide Probability Scale'. Data were analyzed using MANOVA, Pearson correlation test and regression analysis. Results showed that suicide probability, perceived support from friends and significant others and helpless approach scores of the girls were significantly higher than the boys. Besides, significant relationships were found between suicide probability and perceived social support and coping styles. Regression analyses were performed for girls and boys separately. Perceived social support from family, helpless and optimistic styles were found to predict female adolescents' suicide probability significantly. As for male adolescents, in addition to perceived social support from family, helpless and optimistic styles, seeking social support was also found to be a significant predictor of suicide probability. Findings were discussed in line with the related literature, and recommendations were made.
\end{abstract}

Keywords Suicide Probability, Perceived Social Support, Coping Styles, Adolescence

\section{Introduction}

According to the World Health Organization data, [80] suicide, which is an important public health problem, is one of the primary causes of death among adolescents. Both in the world $[20,61,80]$ and in Turkey high death rates due to suicide were found to be in the young population $[4,5,6$, 74]. Of all the suicide cases in Turkey, $34.3 \%$ (1101 people) were in the 15 to 29 age group [74]. It is important to be knowledgeable about the preventive factors and risk factors about suicide probability in order to prevent deadly results in adolescents. Suicide probability, which is defined as a general tendency to kill oneself, enables a new measurement for the conceptualization and assessment of the suicide risk. Suicide probability is defined with the scores obtained from the subscales of suicidal ideation, negative self-evaluation, hostility and hopelessness [17].

Gender is considered an important factor in suicidal ideas and behaviors in adolescents. Studies show higher rates of suicidal ideas and suicide attempts in girls [e.g. 34, $67,80]$, and much higher completed suicide rates in boys $[19,67,80]$. Moreover, the relationship of suicidal ideas and behaviors with important protective and risk factors such as depression and self-respect is known to differ by gender [79]. Therefore, an investigation of both protective factors and risk factors by gender could help to understand suicide probability better. The present study aims to investigate the relationship of social support and coping behaviors, which are among protective factors and risk factors, with suicide probability in adolescents by gender.

Several studies have investigated the effects of social support on mental health $[14,16,21,49]$. As reported by Brugha [10], social support is acknowledged to have beneficial effects on physical and psychological health. Cohen and Wills [14] proposed two models that explain the relationship between social support and health and well-being. One of them is the "stress-buffering model", which suggests that social support affects well-being positively by decreasing negative effects of the social support stressors [14]. According to this theory, individuals who have strong social support systems can better cope with stressful life events in comparison to individuals who have weak social support system $[13,66]$. The other theory is the "main effect model". This model mentions a direct relationship between social support and health and proposes that social support has positive effects on physical health and well-being in all conditions [14].

Studies show that social support is a protective factor that decreases the probability of emergence of maladaptive behaviors in risky cases $[8,45]$. Several studies reported 
that social support perceptions of individuals who attempt suicide were lower [35, 65, 59], and lack of social support is one of the major risk factors for suicidal behaviors [11, $23,27,73]$. Studies indicate that perceived social support particularly from family $[27,55,59,76]$ and friends $[27,76]$ was an important predictor of suicide risk. Özgüven et al. [59] reported that perceived social support from family was lower than the perceived social support from both friends and significant others in individuals who attempted suicide.

Another variable investigated in the study was coping styles. Coping is among risk factors for suicide attempt among adolescents [50]. Coping is defined as the cognitive and behavioral efforts to cope with internal and external demands in times of stressful situations [31]. Coping is the cognitive and behavioral efforts made to master, tolerate, or reduce the emotional stress caused by internal and external stress sources that exceed and consume one's sources [40]. Coping with stress affects adolescents' psychological, physical, and social well-being. Coping with stress affects adolescents' psychological, physical and social well-being [30].

Folkman and Lazarus [32] divide coping methods in two groups as problem-focused and emotion-focused. Problem-focused coping comprises a more active and planned logical analysis that leads to action. The purpose is to cope with the problems that cause trouble. As for emotion-focused coping, it is a passive method which involves the effort for eliminating emotions that developed due to an unwanted event. Both coping methods coexist in individuals' coping patterns, and the method used changes during interaction. While problem-focused behaviors involve active, logical, and conscious efforts for changing the situation; emotion-focused approaches generally involve being away, controlling self, seeking social support, and accepting. Seiffe-Krenke [64] found that there was an increase in the use of both emotion-focused and problem-focused coping strategies in adolescence years. Gibson et al. [36] found that adolescents from 17 countries used problem-focused coping strategies more frequently. Compas, Orosan, and Grant [15] state that use of emotion-focused coping strategies increases in adolescence.

A number of studies show that girls and boys use different ways to cope with stress $[26,37]$. On the other hand, Frydenberg and Lewis [33] found no differences between boys and girls in terms of the use of strategies that focused on finding alternative solutions or changing the environment. However, girls seek more social support than boys, and they use more avoidance strategies. On the other hand, boys were found to act more actively for the solutions to the problems and take more risks.

A number of studies showed that individuals who had suicide probability and who attempted suicide used almost all effective coping methods less [12, 50], turned problems into disasters [51], and had difficulty in providing options to the problems [43] in comparison to the ones in the control group. Suicide risk is negatively associated with redefining the problem by dividing it into little parts and finding alternatives, one of the coping styles [12]. Horesh et al. [43] found that individuals with suicide probability used less coping methods in terms of planning the problem and dividing it into parts, were inadequate in decreasing the effects of the problem or source of stress, and had lack of ability of obtaining new information.

Curry, Miller, Waugh, and Anderson [18] found that in their struggles with stressful situations, adolescents with suicide probability used emotion-focused methods rather than problem-focused ones, and that problem-focused coping was associated with low suicidality. It is emphasized that individuals with suicidality use avoidance strategies in case of problems. Orbach, Bar-Joseph, and Dror [58] reported that avoidance was a general coping style of those who attempted suicide and those who had suicidal ideas. Individuals who have high suicide probability give negative emotional reactions and use avoidance method as a problem solving strategy. Edwards and Holden [24] found that emotion-oriented coping and avoidance-distraction methods are associated with suicide probability.

The current study examined the relationship among perceived social support, coping styles and suicide probability in adolescents by gender. Fennig et al. [29] state that identification of the risk factors for both genders separately could help to explain the reasons for the differences between male and female suicidal behaviors. There are two studies on this issue conducted in Turkey [2, 7]. Both studies, which investigated suicide probability by gender in terms of various risk factors, were conducted with adults; they investigated suicide probability in terms of interpersonal communication styles, reasons for maintaining life, hopelessness, loneliness, and social support and gender roles variables. The present study was conducted with adolescents, and no studies in Turkey were found to focus on adolescents in this issue. Besides, much of the research to date has focused on the associations of social support and coping to actual suicide but not to probability. Hence, this study aims to find answers to the following questions:

(1) Do adolescents' suicide possibility, perceived social support (from family, friends and significant others) and coping styles (self-confident style, optimistic style, helpless style, submissive style, seeking social support style) differ by gender?

(2) How much do the perceived social support and coping styles in adolescents predict suicide probability?

(3) Are there gender differences in the relationships among perceived social support, coping styles, and suicide probability in adolescents? 


\section{Method}

\subsection{Participants}

This study was conducted in Adana, a city located in the Mediterranean region of Turkey. This region is among the places with high suicide rates [74]. The participants of the study included 227 girls (51\%) and 218 boys (49\%), a total of 445 students in Grades 9 to 12 from four public high schools in Adana central province, Turkey. Their ages ranged from 14 to 18 years $(\mathrm{M}=15.90, \mathrm{SD}=.87)$. Average age of the female students was $15.82(\mathrm{SD}=.85)$ and that of males was $15.98(\mathrm{SD}=.91)$. Average age scores indicated no significant differences between males and females $(t=-1.90, p>.05)$. Of all the students participating in the study, 140 were $9^{\text {th }}$ graders $(31.5 \%), 124(27.9 \%)$ were $10^{\text {th }}$ graders, $104(23.4 \%)$ were $11^{\text {th }}$ graders and 77 $(17.3 \%)$ were $12^{\text {th }}$ graders. The majority of participants reported that their parents were married $(94.6 \%)$ ). Furthermore, $5.2 \%$ of participants' parents were divorced, and $4.3 \%$ of participants had a parent who was deceased. One class from all class levels were chosen randomly among the schools and the forms were administered to volunteer students.

\subsection{Measures}

\subsubsection{The Suicide Probability Scale (SPS)}

The SPS [17] is a self-report measure that assesses suicide risk in adolescents and adults. The 36-item scale consists of four subscales: hopelessness, suicidal ideation, negative self-evaluation, and hostility. All questions on the SPS are responded to using a 4-point Likert scale ranging from none or a little of the time (1) to most or all of the time (4). The SPS was adapted into Turkish by Tuğcu [75]. Cronbach's alpha coefficients were between .49 and .75 for the subscales and .87 for the total score.

\subsubsection{Multidimensional Scale of Perceived Social Support} (MSPSS)

The MSPSS was developed by Zimet, Dahlem, Zimet and Farley [84] and aims to measure perceived social support from three sources: family, friends, and a significant other. The 12-item scale consists of three subscales: perceived family support, perceived friends support and perceived significant other support. Each item is rated on a 7-point Likert-type response format, ranging from very strongly disagree (1) to very strongly agree (7). Higher scores indicate more perceived social support. The scale was adapted to Turkish by Eker and Arkar [25].
Cronbach's alpha coefficients were between .80 and .95 for the total scale and the sub-scales.

\subsubsection{Ways of Coping with Stress Inventory (WCSI)}

The WCSI is derived from the Ways of Coping Inventory [31] which is adopted into Turkish by Şahin and Durak [72]. Each item is rated on a 4-point Likert-type response format. The scale is consisted of 30 items and five subscales; Self-Confident, Optimistic, Helpless, Submissive, and Seeking of Social Support. The self-confident, optimistic and social support seeking approaches are considered as effective ways of coping with problems; helpless approach and submissive approach are considered as ineffective/emotion focused ways of coping. Cronbach's alpha reliability scores for CSS sub-scales are “.62-.80” for Self-confident Style, “.49-.68” for Optimistic Style, “.64-.73" for Helpless Style, ".47- .72" for Submissive Style, and ".45-.47" for Seeking Social Support Style [72].

\subsection{Data Analysis}

Means and standard deviation distributions were investigated. MANOVA, Pearson product moment correlations, and regression analyses were performed. Histogram and normality assumptions were examined and found to be satisfactory. The analysis was carried out using SPSS version 22.0.

\section{Results}

\subsection{Gender Differences in Suicide Probability, Social Support and Coping Styles}

To assess differences in suicide probability, social support and coping styles as a function of gender, MANOVA was conducted. Equality of variance was acceptable based on Box's M (Box's $\mathrm{M}=51.72 ; \mathrm{F}=1.13$, $p>.05)$. MANOVA results of analysis revealed that there were significant differences according to gender in respect of suicide probability, social support and coping styles (Wilk's Lambda $\left.(\Lambda)=0.893, F_{(1,443)}=5.77, p<.001\right)$. Table 1 shows the results from a factorial one-way ANOVA depending on gender and means and standard deviations of the variables. As shown in Table 1, the girls reported being more perceived social support from friends $(\mathrm{F}=12.46$, $\mathrm{p}<.001)$ and significant others $(\mathrm{F}=5.06, \mathrm{p}<.05)$ and having greater suicide probability than did the boys $(\mathrm{F}=4.80$, $\mathrm{p}<.05)$. 
Table 1. F results of MANOVA depending on gender

\begin{tabular}{|c|c|c|c|c|c|c|c|}
\hline & Gender & $\mathrm{N}$ & $\mathrm{X}$ & SD & $\mathrm{df}$ & $\mathrm{F}$ & $\mathrm{p}$ \\
\hline \multirow{2}{*}{ Suicide probability } & M & 218 & 69.05 & 16.06 & \multirow{2}{*}{$1-443$} & \multirow{2}{*}{4.80} & \multirow{2}{*}{$.029 *$} \\
\hline & $\mathrm{F}$ & 227 & 72.44 & 16.62 & & & \\
\hline \multirow{2}{*}{ Perceived social support from family } & M & 218 & 19.68 & 6.77 & \multirow{2}{*}{$1-443$} & \multirow{2}{*}{.61} & \multirow{2}{*}{.606} \\
\hline & $\mathrm{F}$ & 227 & 19.16 & 7.31 & & & \\
\hline \multirow{2}{*}{ Perceived social support from friends } & $\mathrm{M}$ & 218 & 18.50 & 6.65 & \multirow{2}{*}{$1-443$} & \multirow{2}{*}{12.46} & \multirow{2}{*}{$.000 * *$} \\
\hline & $\mathrm{F}$ & 227 & 20.68 & 6.42 & & & \\
\hline \multirow{2}{*}{ Perceived social support from significant others } & M & 218 & 17.60 & 7.02 & \multirow{2}{*}{$1-443$} & \multirow{2}{*}{5.06} & \multirow{2}{*}{$.025^{*}$} \\
\hline & $\mathrm{F}$ & 227 & 19.16 & 7.60 & & & \\
\hline \multirow{2}{*}{ Self-confident style } & $\mathrm{M}$ & 218 & 14.90 & 3.26 & \multirow{2}{*}{$1-443$} & \multirow{2}{*}{.324} & \multirow{2}{*}{.569} \\
\hline & $\mathrm{F}$ & 227 & 15.07 & 3.10 & & & \\
\hline \multirow{2}{*}{ Optimistic style } & M & 218 & 10.11 & 2.52 & \multirow{2}{*}{$1-443$} & \multirow{2}{*}{.504} & \multirow{2}{*}{.478} \\
\hline & $\mathrm{F}$ & 227 & 9.93 & 2.71 & & & \\
\hline \multirow{2}{*}{ Helpless style } & M & 218 & 11.87 & 4.32 & \multirow{2}{*}{$1-443$} & \multirow{2}{*}{24.19} & \multirow{2}{*}{$.000 * *$} \\
\hline & $\mathrm{F}$ & 227 & 13.82 & 4.03 & & & \\
\hline \multirow{2}{*}{ Submissive style } & M & 218 & 6.50 & 3.23 & \multirow{2}{*}{$1-443$} & \multirow{2}{*}{.94} & \multirow{2}{*}{.332} \\
\hline & $\mathrm{F}$ & 227 & 6.79 & 3.23 & & & \\
\hline \multirow{2}{*}{ Seeking of social support style } & M & 218 & 7.33 & 2.21 & \multirow{2}{*}{$1-443$} & \multirow{2}{*}{1.86} & \multirow{2}{*}{.277} \\
\hline & $\mathrm{F}$ & 227 & 7.56 & 2.39 & & & \\
\hline
\end{tabular}

Note: $\mathrm{M}=$ Male, $\mathrm{F}=$ Female, $* \mathrm{p}<.05, * * \mathrm{p}<.001$

Table 2. Correlations of predictor and criterion variables for total sample

\begin{tabular}{|c|c|c|c|c|c|c|c|c|c|}
\hline & 1 & 2 & 3 & 4 & 5 & 6 & 7 & 8 & 9 \\
\hline 1. Suicide probability & - & & & & & & & & \\
\hline 2. Perceived social support from family & $-.42 * * *$ & - & & & & & & & \\
\hline 3. Perceived social support from friends & $-.19 * * *$ & $.37 * * *$ & - & & & & & & \\
\hline $\begin{array}{l}\text { 4. Perceived social support from significant } \\
\text { others }\end{array}$ & $-.18 * * *$ & $40 * * *$ & $.51 * * *$ & - & & & & & \\
\hline 5. Self-confident style & $-.30 * * *$ & $.25^{* * *}$ & $.23 * * *$ & $.22 * * *$ & - & & & & \\
\hline 6. Optimistic style & $-.35 * * *$ & $.30 * * *$ & $.15^{* *}$ & $.14 * *$ & $.58 * * *$ & - & & & \\
\hline 7. Helpless style & $.56 * * *$ & $-.28 * * *$ & $-.13 * *$ & $.22 * *$ & $-.29 * * *$ & $-.24 * * *$ & - & & \\
\hline 8. Submissive style & $.36 * * *$ & $-.18 * * *$ & $-.11^{*}$ & $.22 *$ & $-.33 * * *$ & $-.15 * *$ & $.53 * * *$ & - & \\
\hline 9. Seeking of social support style & $-.26^{* * *}$ & $.26 * * *$ & $.33 * * *$ & $.27 * * *$ & $.32 * * *$ & $.20 * * *$ & $-.26 * * *$ & $-.25 * * *$ & - \\
\hline M & 70.78 & 19.41 & 19.61 & 18.40 & 14.99 & 10.02 & 12.86 & 6.65 & 7.45 \\
\hline SD & 16.42 & 7.05 & 6.62 & 7.35 & 3.17 & 2.62 & 4.28 & 3.23 & 2.31 \\
\hline
\end{tabular}

$* \mathrm{p}<.05, * * \mathrm{p}<.01, * * * \mathrm{p}<.001$ 


\subsection{Relationships of Suicide Probability, Social Support and Coping Styles}

Pearson product-moment correlations were computed for the scores on the Suicide Probability Scale $(M=70.78$, $\mathrm{SD}=16.42)$, those on each of three social support scales: Family $(\mathrm{M}=19.41, \mathrm{SD}=7.05)$, friends $(\mathrm{M}=19.61, \mathrm{SD}=$ $6.62)$, significant others $(\mathrm{M}=18.40, \mathrm{SD}=7.35)$ and those on each of five coping styles: Self-confident $(\mathrm{M}=14.99$, $\mathrm{SD}=3.17)$, optimistic $(\mathrm{M}=10.02, \mathrm{SD}=2.62)$, helpless $(\mathrm{M}$ $=12.86, \mathrm{SD}=4.28)$, submissive $(\mathrm{M}=6.65, \mathrm{SD}=3.23)$, seeking of social support $(\mathrm{M}=7.45, \mathrm{SD}=2.31)$. The findings indicated that there were negative significant correlations between suicide probability and perceived social support from family $(\mathrm{r}=-.42, \mathrm{p}<.001)$, perceived social support from friends $(\mathrm{r}=-.19, \mathrm{p}<.001)$, perceived social support from significant others $(\mathrm{r}=-.18, \mathrm{p}<.001)$, self-confident style $(\mathrm{r}=-.30, \mathrm{p}<.001)$, optimistic style $(\mathrm{r}=$ $-.35, \mathrm{p}<.001)$, seeking of social support style $(\mathrm{r}=-.26$, $\mathrm{p}<.001)$, and positive correlations between suicide probability and helpless style $(\mathrm{r}=.56, \mathrm{p}<.001)$, submissive style $(\mathrm{r}=.36, \mathrm{p}<.001)$.

The stepwise multiple linear regression analysis, which examined suicide probability according to the MSPSS and the WCSI for whole sample, is as shown in Table 3. The stepwise regression analysis results indicated that three variables contributed meaningfully to suicide probability.
Results revealed that, low level of perceived social support from family $((\beta=-.24, p<.001)$, helpless style $(\beta=.45$, $\mathrm{p}<.001)$, and optimistic style $(\beta=-.17, \mathrm{p}<.001)$ emerged as important predictors for suicide probability. Predictor variables account for $41 \%$ of the total variance $\mathrm{F}_{(8,444)}=$ $102.98, \mathrm{p}<.001$.

To assess for gender differences in predicting suicide probability, the aforementioned multiple regression models were run separately for males and females. As shown in Table 3, the stepwise regression analysis results indicated that four variables contributed meaningfully to suicide probability for males. According to the standardized regression coefficient ( () , variables that affect suicide probability are the perceived social support of family ( $\beta=-.22)$, the helpless style $(\beta=.47)$, seeking of social support style $(\beta=-.12)$ and optimistic style $(\beta=-.12)$. Predictor variables together, explain $44 \%$ of the variance in suicide probability $\mathrm{F}_{(8,444)}=43.04, \mathrm{p}<.001$.

In the females the stepwise regression analysis results indicated that three variables contributed meaningfully to suicide probability. Results revealed that, perceived social support from family $((\beta=-.25, \mathrm{p}<.001)$, helpless style $(\beta=.38, p<.001)$, and optimistic style $(\beta=-.20, p<.001)$ emerged as important predictors for suicide probability. Predictor variables account for $38 \%$ of the total variance $\mathrm{F}$ $(8,444)=46.19, \mathrm{p}<.001$.

Table 3. Regression model for effect of social support and coping styles on suicide probability

\begin{tabular}{|l|c|c|c|c|c|c|}
\hline & $\mathbf{R}^{2}$ & $\boldsymbol{R}_{\text {adj }}^{2}$ & $\mathbf{R}_{\text {change }}$ & Beta & $\mathbf{T}$ & \multicolumn{1}{|c|}{$\mathbf{~}$} \\
\hline Whole sample & & & & & & \\
\hline Perceived social support from family & .18 & .17 & .18 & -.24 & $-6.23^{* *}$ & $93.79^{* *}$ \\
\hline Helpless style & .39 & .38 & .21 & .45 & $11.72^{* *}$ & $139.66^{* *}$ \\
\hline Optimistic style & .41 & .41 & .03 & -.17 & $-4.31^{* *}$ & $102.98^{* *}$ \\
\hline Male & & & & & & \\
\hline Perceived social support from family & .17 & .16 & .17 & -.22 & $-4.03^{* *}$ & $43.07^{* *}$ \\
\hline Helpless style & .42 & .41 & .25 & .47 & $8.65^{* *}$ & $77.25^{* *}$ \\
\hline Seeking of social support style & .44 & .43 & .02 & -.12 & $-2.14^{*}$ & $54.94^{* *}$ \\
\hline Optimistic style & .45 & .44 & .01 & -.12 & $-2.14 *$ & $43.04^{* *}$ \\
\hline Female & & & & & & \\
\hline Perceived social support from family & .18 & .18 & .18 & -.25 & $-4.32^{* *}$ & $49.81^{* *}$ \\
\hline Helpless style & .35 & .34 & .17 & .38 & $6.68^{* *}$ & $59.83^{* *}$ \\
\hline Optimistic style & .38 & .38 & .04 & -.20 & $-3.56^{* *}$ & $46.19^{* *}$ \\
\hline & & & & & & \\
\hline
\end{tabular}

$* \mathrm{p}<.05, * * \mathrm{p}<.001$ 


\section{Discussion}

The present study mainly investigated whether suicide probability, perceived social support and coping styles differ by gender. Girls' suicide probability, perceived social support from friends and significant others, and helpless style scores were found to be significantly higher in comparison to boys. Gender was found to be an important predictor of suicidal behaviors [83]. Related literature indicates that nonfatal suicide attempts are much common in women than men both in Turkey and in the world [e.g. 74, 83]. Besides, several studies report that women have more suicidal ideas than men [e.g. 41, 78]. The finding of this study indicating female adolescents' higher suicide probability is in line with the related literature.

Similar to the results of this study, a number of studies indicated that high school students' perceived social support from family did not differ by gender [e.g. 22, 47, 71], and girls' perceived support from friends was found to differ in favor of girls [e.g. 46, 56, 63, 71]. While generally adolescents spent more time with their friends, girls established deeper and more consistent relationships in small groups, and boys tended to be in different and large friends groups in line with their interests [82]. The difference in favor of girls might result from the fact that girls are more attached to their friends and share more things with each other in comparison to boys. Girls' perceived social support from significant others were found to be higher in comparison to boys. Boys' weaker perceived social support from friends and significant others could result from the fact that boys generally tend to solve their problems by themselves.

Only the use of helpless style among coping styles demonstrated difference by gender. Parallel to several studies in literature [e.g. 1;60, 81], the present study also found that girls used helpless style more than boys. Girls' using this style in stressful situations more than boys could be associated with traditional gender roles.

As expected, a negative relationship was found between perceived social support from different areas and suicide probability. Besides, suicide probability is positively associated with ineffective coping styles (helpless and submissive) and negatively associated with effective coping styles (self-confident, optimist and seeking social support). The main purpose of this study is to identify the role of perceived social support and coping styles in predicting suicide probability in female and male adolescents. A number of analyses were performed in line with this general purpose. Results of the regression analysis which was conducted for all participants showed that lack of use of perceived support from family and optimistic style and higher use of helpless style are significant indicators of suicide probability. Regression analysis performed for boys and girls separately showed that lack of use of perceived support from family and optimistic style and higher use of helpless style are seen as the common predictors of suicide probability in both girls and boys. Differently, lack of use of seeking social support style among boys was found to be a predictor of suicide probability.

Studies show that social support promotes physical and psychological health [53, 57, 70, 77], and adolescents with high social support levels demonstrated less anxiety and depression symptoms and behavioral problems [8]. Terzi Ünsal and Kapçı [73] report that lack of social support is an important risk factor in adolescents; it is also a secondary risk factor in adolescent suicides. A number of studies found a negative relationship between social support and suicidal ideas and behaviors [e.g. 44, 68, 53]. Family is the fundamental and primary source of support, and is associated with low suicidal ideas [48]. Although friends and significant others are an important source of support for adolescents [28], several studies indicate that family support is a more important source than friend support in traumatic situations [e.g. 3, 52, 62]. Lai and Ma [52] stated that while perceived support from family was a predictor of suicidal ideas, perceived support from friends and significant others were not. Adolescents' family relationships, warmth and support they receive from their parents are some of the fundamental factors on their well-being; insufficient family support could increase their feelings of rejection, hopelessness, and loneliness. Hence, Helsen Vollebergh, and Meeus [42] reported that parent support was the strongest predictor of the problems experienced in adolescence. Besides, Soylu et al. [68] remarked that perception of low family support and suicide attempt are closely associated, and suicide attempt was higher in individuals with low family and social support. In a similar vein, Rojas et al. [62] reported that both suicidal ideas and suicide attempts are associated with perceived lack of support from parents. In line with these studies, perception of high family support, by enabling a sheltered environment in troubled times, could decrease suicide probability in both female and male adolescents.

"Helpless" and "Optimistic" styles were the most important predictors of suicide probability in both female and male adolescents. Individuals who use helpless style for coping, which is an ineffective approach in coping with stress, withdraw in cases of stress, avoid facing with the problem, and wait for the stressful situation to pass. Related literature includes a number of studies which indicate a negative relationship between psychological well-being and use of helpless style, which is an emotion-focused style [e.g. 9, 39]. Studies which investigate the relationships between suicide behaviors and coping styles [e.g. 18, 24, 58] showed that individuals with suicide probability used more emotion-focused coping strategies (e.g. avoidance), namely maladaptive strategies, which is in line with the results of this study.

High levels of use of "optimistic style", which is considered an effective method in coping with stress, 
decrease suicide probability in both female and male adolescents. Individuals who use optimistic style are people who can control themselves in times of stressful situations, assess events in a logical way, and have positive attitudes [72]. Güç [38] found that using optimistic style predicted attitudes of seeking psychological help. Studies show that individuals with suicide probability used almost all effective coping methods less [12, 50], and had difficulty in providing options to the problems [43].

Different from female adolescents, seeking social support style was found to be a significant predictor of suicide probability in male adolescents. Suicide probability was found to increase in males who use seeking social support less. Studies show that male adolescents sought less social support [33], and had more negative help-seeking behaviors [54]. This finding could be associated with social roles attributed to males such as being strong and independent.

Like all studies, the present study has a number of limitations. First of all, the scales used in this study are self-report scales. Next, the sample is composed of schools in a city center in Turkey, which does not identify all adolescents. Random selection from various regions is needed so that the results can be generalized.

This study investigated suicide probability in adolescents by gender. Based on the findings of the study, it is recommended that programs for suicide prevention should include psycho-educational programs on developing effective coping styles. Preparing and implementing psycho-educational programs that increase coping skills contribute to decrease suicide probability. Programs for male adolescents could include activities that promote use of seeking social support style. Besides, education programs that inform parents about the social support to be provided to adolescents are of importance in terms of adolescents' psychological health.

\section{REFERENCES}

[1] Akbağ, M. (2000). An Investigation of the coping styles of the university students in terms of negative automatic thoughts, ego states in transactional analysis and other variables. Unpublished doctoral thesis, Marmara University, Turkey.

[2] Arsel, C.O. (2010). Suicide probability and gender: Evaluation in terms of interpersonal style, sex roles, social support and hopelessness Unpublished master thesis. Ankara University, Turkey.

[3] Bal, S., Crombez, G., Van Oost, P. \& De Bourdeaudhuij, I. (2003). The role of social support in well-being and coping with self-reported stressful events in adolescents. Child Abuse and Neglect, 27(12), 1377-1395.

[4] Bağl1, M. (2004). Conceptualization of the freedom and social structure on the basis of suicides in Batman. Journal of
Crisis, 12 (1), 21-40.

[5] Batıün, A.D. (2002). Youth and suicide: Differences in comparison with other age groups. Unpublished doctoral thesis, Ankara University, Turkey

[6] Batıün, A.D (2005). Suicide probability: An assessment terms of reasons for living, hopelessness and loneliness. Turkish Journal of Psychiatry, 16(1), 29-39.

[7] Batıün, A.D. (2008). Suicide risk and gender: An evaluation of suicide in respect to interpersonal relationship style, reasons for living, loneliness, and hopelessness. Turkish Journal of Psychology, 23 (62), 65-75

[8] Barrera, M., Fleming, C.F. \& Khan, F.S. (2004). The Role of Emotional Social Support in the Psychological Adjustment of Siblings of Children with Cancer. Child Care Health Development, 30(2), 103-111.

[9] Ben-Zur, H. (2005). Coping, distress, and life events in a community sample. International Journal of Stress Management, 12, 188-196.

[10] Brugha, T.S. (1988). Social support. Current Opinion in Psychiatry, 1, 206-211.

[11] Bjarnason, T. (1994). The influence of social support, suggestion and depression on suicidal behaviour among Icelandic youth. Acta Sociologica, 37, 195-206.

[12] Botsis, A.J., Soldatos, C.R., Liossi, A., Kokkevi, A. \& Stefanis, C.N. (1994). Suicide and violence risk: I. relationship to coping styles. Acta Psychiatrica Scandinavica, 89, 92-96.

[13] Callaghan, P. \& Morrissey, J. (1993). Social Support and Health: A Review. Journal of Advanced Nursing, 18, 203-210.

[14] Cohen, S. \& Wills, T.A. (1985). Stress, social support, and the buffering hypothesis. Psychology Bulletin, 98, 310-357.

[15] Compas, B., Orosan, P.G., \& Grant, K.E. (1993). Adolescent stress and coping: Implications for psychopathology during adolescence. Journal of Adolescence. 16, 331-349.

[16] Coyne, J. C., \& Downey, G. (1991). Social factors and psychopathology: Stress, social support, and coping processes. Annual Review of Psychology, 42, 401-425.

[17] Cull, J. G. \& Gill, W. S. (1990). Suicide Probability Scale Manual. Western Psychological Services, Los Angeles.

[18] Curry, J. F., Miller, Y., Waugh, S., Anderson, W.B. (1992). Coping responses in depressed, socially maladjusted, and suicidal adolescents, Psychological Reports, 71,1, 80-82

[19] Çuhadaroğlu, F.Ç. \& Sonuvar, B. (1992). Adolescent suicides: A review on risk factors. Turkish Journal of Psychiatry, 3 (3), 222-226.

[20] Dixon, W. A., Rumford, K. G., Heppner, P. P., \& Lips, B. J. (1992). Use of different sources of stress to predict hopelessness and suicide ideation in a college population. Journal of Counseling Psychology, 39, 342-349.

[21] Doğan, T. (2008). Social support and wellness as predictors of psychological symptoms. Turkish Psychological Counseling and Guidance Journal, 3(30), 30-44 
[22] Dülger Ö (2009). Correlation between perceived social support and decision making behavior of adolescents. Unpublished master thesis, Marmara University, Turkey

[23] D’Attilio, J.P., Campbell, B.M., Lubold, P., Jacobson, T. \& Richard, J.A. (1992). Social support and suicide potential: Preliminary findings for adolescent populations. Psychological Reports, 70, 76-78.

[24] Edwards M.J. \& Holden RR. (2001). Coping, meaning in life, and suicidal manifestations: Examining gender differences. Journal of Clinical Psychology, 57(12), 1517-34.

[25] Eker, D. \& Arkar, H. (1995). Factorial structure, validity, and reliability of Multidimensional Scale of Perceived Social Support. Turkish Journal of Psychology, 34, 45-55.

[26] Eshun, S. (2000). Role of gender and rumination in suicide ideation: A comparison of college samples from Ghana and the United States. Cross-Cultural Research: The Journal of Comparative Social Science, 34, 250-263.

[27] Eskin, M. (1995). Suicidal behavior as related to social support and assertiveness among Swedish and Turkish high school students: A cross-cultural investigation. Journal of Clinical Psychology, 51, 2, 158-172.

[28] Fatoba, E. \& Bzdzikot, D. (2015). Stress and social support systems among final year medical students of Medical University of Silesia. BMC Proceedings, 9, A57.

[29] Fennig, S., Geva, K., Zalsman, G., Weizman, A., Fennig, S. \& Apter, A. (2005). Effect of gender on suicide attempters versus nonattempters in an adolescent inpaitent unit. Comprehensive Psychiatry, 46, 90-97.

[30] Folkman S. \& Lazarus R. S. (1980) An analysis of coping in a middle-aged community sample. Journal of Health and Social Behavior, 21, 219- 239.

[31] Folkman S. \& Lazarus R. S. (1985) If it changes it must be a process: a study of emotion and coping during three stages of a college examination. Journal of Personality and Social Psychology 48: 150-170.

[32] Folkman, S., \& Lazarus, R. S. (1986). Stress processes and depressive symptomatology. Journal of Abnormal Psychology, 95, 107-113.

[33] Frydenberg, E., \& Lewis, R. (1991). Adolescent coping: The different ways in which boys and girls cope. Journal of Adolescence, 14, 119- 133.

[34] Garrison, C.Z., McKeown, R.E., Valois, R.F. \& Vincent, M. L. (1993). Aggression, substance use, and suicidal behaviors in high school students. American Journal of Public Health, $83,179-84$.

[35] Gaspari V.P.P., Botega N.J. (2002). Social support and attempted suicide. Jornal Brasileiro de Psiquiatria, 51(4), $233-240$

[36] [36] Gibson, J.T., Baker, C.E., Showalter, S.M., Al-Sarraf, Q., Atakan, S.A., et. al. (1992). Gender and culture: Reported problems, coping strategies and selected helpers of male and female adolescents in 17 countries. International Journal of the Advancement of Counseling, 15 (3), 137-149.

[37] Govender, K. \& Killian, B.J. (2001). The psychological effects of chronic violence on children living in South
African townships. South African Journal of Psychology 31(2):1-24.

[38] Güç, E. (2015). Investigation of university students self-stigmatization, coping with stress styles and attitudes toward psychological help-seeking. Unpublished master thesis, Ankara University, Turkey

[39] Gürdil, G. (2007). Relationship among traumatic experiences, ways of coping, internal-external locus of control beliefs and hazardous alcohol use in university students. Unpublished master thesis, Hacettepe University, Turkey

[40] Haines, J., \& Williams, C.L. (1997). Coping and problem solving of self-mutilators. Journal of. Clinical Psychology, $53,177-186$.

[41] He, Z. X. \& Lester, D. (2001). Sex differences in suicidal ideation in a community sample from China. Crisis, 22 (3), 132-134.

[42] Helsen, M., Vollebergh, W., \& Meeus, W. (2000). Social support from parents and friends and emotional problems in adolescence. Journal of Youth and Adolescence, 29, 319-335.

[43] Horesh, N., Rolnick, T., Iancu, I., Dannon, P., Lepkifker, E., Apter, A. \& Kotler, M. (1996).Coping styles and suicide risk. Acta Psychiatrica Scandinavica, 93, 489-493.

[44] Hur, J.W., Kim, W.J. \& Kim, Y.K. (2011). The mediating effect of psychosocial factors on suicidal probability among adolescents. Archives of Suicide Research, 15,327-336

[45] Jackson, Y., \& Warren, J.S. (2000). Appraisal, social support, and life events: Predicting outcome behavior in school-age children. Child Development, 71, 1441-1457.

[46] Kahriman, İ. (2003). The relationship between the self-esteem and the perceived social support adolescents received from their families and friends. Unpublished master thesis, Atatürk University, Turkey

[47] Karacabey, Ç. (2012). This research is made for the examination of relation between the secondary education students whom get social supports from their family and their behavior of suicide probability. Unpublished master thesis, Yeditepe University, Turkey

[48] Kerr, R., Garvin, J., Heaton, N. \& Boyle, E. (2006). Emotional intelligence and leadership effectiveness. Leadership \& Organisation Development Journal, 27(4), 265-279.

[49] Kessler, R.C., Borges, G. \& Walters, E.E. (1999). Prevalence of and risk factors for lifetime suicide attempts in the National Comorbidity Survey. Archives of General Psychiatry, 56, 617-626.

[50] Kim, H.S. \& Kim, H.S. (2008). Risk factors for suicide attempts among Korean adolescents. Child Psychiatry Human Development, 39,221-235.

[51] Kotler, M., Finkelstein, G., Molcho, A., Botsis, A. J., Plutchik, R., Brown, S. L. \& van Praag, H. M. (1993).Correlates of suicide and violence risk in an inpatient population: Coping styles and social support. Psychiatry Research, 47, 281-290.

[52] Lai, C.C.W. \& Ma, C. (2016). The mediating role of social 
support in the relationship between psychological well-being and health-risk behaviors among Chinese university students. Health Psychology Open, July-December, 1-11

[53] Lewis M (2002) Suicidal behavior in children and adolescents: Causes and management. Third edition, Philadelphia: Lippincott Williams \& Wilkins, 796-805.

[54] Mojaverian, T., Hashimoto, T. \& Kim, H.S. (2012). Cultural differences in professional help seeking: A comparison of Japan and the U.S. Frontiers in Psychology, 3, 615.

[55] Morano, C.D., Cisler, B.A. \& Lemerond, J. (1993). Risk factors for adolescent suicidal behavior: Loss, insufficient familial support and hopelessness. Adolescence, 28, $851-865$

[56] Newman, B., Newman, P., Griffen, S., O’Connor, K. \& Spas, J. (2007). The relationship of social support to depressive symptoms during the transition to high school. Adolescence, $42,441-460$.

[57] Nickerson, A. B., \& Nagle, R. J. (2004). The influence of parent and peer attachments on life satisfaction in middle childhood and early adolescence. Social Indicators Research, $66,35-60$.

[58] Orbach, I., Bar-Joseph, H. \& Dror, N. (1990). Styles of Problem Solving in Suicidal Individuals. Suicide and Life-Threatening Behavior, 20(1), 56-64.

[59] Özgüven, H.D., Soykan, Ç., Haran, S. \& Gençöz, T. (2003). Importance of problem solving skills, perceived social support, and depression and anxiety symptoms on suicide attempts. Turkish Journal of Psychology, 18(52), 13-15.

[60] Özyürek, A. (2013). An examination of adolescents' methods of coping with stress. IIB International Refereed Academic Social Sciences Journal, 9 (4): 85-100

[61] Range, L. M. \& MacIntyre, D. I., Rutherford, D., Billie, S., Payne, B., Knott, E., Brown, M. \& Foster, C. L. (1997). Suicide in special populations an circumstances: A review. Aggression and Violent Behavior, 2 (1), 53-63.

[62] Rojas, S.M., Bilsky, S.A., Dutton, C., Badour, C.L., Teldner, M. T. \& Leen-Feldner, E.W. (2017). Lifetime histories of PTSD, suicidal ideation, and suicide attempts in a nationally representative sample of adolescents: Examining indirect effects via the roles of family and peer social support. Jourmal of Anxiety Disorders, 49, 95-103.

[63] Sayar, M. (2006). A longitudinal study of the relationship between perceived social support and psychological well-being of adolescent from low socioeconomic status. Unpublished master thesis, Boğaziçi University, Turkey

[64] Seiffge-Krenke, I. (1993). Coping behavior in normal and clinical samples: More similarities than differences? Journal of Adolescence, 16, 285-303

[65] Seydioğlu, M. (2002). The Evaluating of attempt suicide via depression and social support, and researching their sociodemographic characteristics. Unpublished master thesis, Yüzüncü Y1l University, Turkey

[66] Shonkoff, J. P. (1984). Social support and the development of vulnerable children. American Journal Public Health, 74(4), 310-312.
[67] Skogman, K., Alsen, M., \& Ojehagen, A. (2004). Sex differences in risk factors for suicide after attempted suicide: A follow-up study of 1052 suicide attempters. Social Psychiatry and Psychiatric Epidemiology, 39, 113-120.

[68] Soylu, N., Taneli, Y. \& Taneli, S. (2013). Investigation of social, emotional, and cognitive factors with effect on suicidal behaviour in adolescents with depression. Archives of Neuropsychiatry, 50, 291-294.

[69] Stokes, J. P. (1985). The relation of social network and individual difference variables to loneliness. Journal of Personality and Social Psychology, (48), 981-990.

[70] Suominen, S.B., Valimaa, R.S. \& Helenius, H.Y. (2005). Factors associated with perceived health among 12-year-old school children: Relevance of physical exercise and sense of coherence. Scandinavian Journal of Public Health 33, 35-41.

[71] Sürücü, M. (2005). High school students' vocational maturity and perceived social support level. Unpublished master thesis, Gazi University, Turkey

[72] Şahin, N.H, \& Durak, A. (1995). A Brief Coping Styles Inventory for university students. Turkish Journal of Psychology, 10(34), 56-73.

[73] Terzi-Ünsal, S \& Kapçı, E.G. (2005). Risk factors for suicidal behavior: Psychosocial risk models with Turkish adolescents. Social Behavior and Personality: An international journal, 33(6), 593-608.

[74] The National Statistics Institute-TUIKK (2015). Turkey Statistics Institute suicide statistics. http://www.tuik.gov.tr/PreHaberBultenleri.do?id=21516 downloaded on 01 March 2017.

[75] Tuğcu, H. (1996). The probalility of suicide in relation to factors in normal and depressive persons. Unpublished doctoral thesis, Hacettepe University, Turkey.

[76] Tüzün, Z. (1997). Life events, depression, social support systems, reasons for living and suicide probability among university students. Unpublished master thesis, The Graduate School of Social Sciences of The Middle East Technical University, Turkey.

[77] Uchino, B. N., Cacioppo, J. T., \& Kiecolt-Glaser, J. K. (1996). The relationship between social support and physiological processes: A review with emphasis on underlying mechanisms and implications for health. Psychological Bulletin, 119, 488-531.

[78] Uçar, N. (1999). Correlates of suicide ideation and relation to ego identity status among adolescents. Unpublished master thesis, The Graduate School of Social Sciences of The Middle East Technical University, Turkey.

[79] Wichstrom, L. \& Roossow, I. (2002). Explaining the gender difference in self- reported suicide attempts. Suicide Life Threatening Behavior, 32 (2), 101-116

[80] World Health Organization (2015). Suicide rates. http://www.who.int/gho/mental health/suicide_rates/en/do wnloaded on 20 March 2017

[81] Yerlikaya N. (2007). The relationship between humor styles and coping styles of high school students. Unpublished master thesis, Çukurova University, Turkey.

[82] Zaslow, M.J. \& Takanishi, R. (1993). Priorities for Research 
on Adolescent Development. American Psychologist, 48(2), 185-192.

[83] Zhang, J., McKown, R.E., Hussey, J.R., Thompson, S.J. \& Woods, J.R. (2005). Gender differences in risk factors for attempted suicide among young adults: Findings from the

i This study was presented at the International Conference on New Horizons in Education held in Berlin, Germany on July 17-19, 2017.
Third National Health and Nutrition Examination Survey. Annuals of Epidemiology, 15, 167-174.

[84] Zimet, G.D., Dahlem, N.W., Zimet, S.G. \& Farley, G.K. (1988). The Multidimensional Scale of Perceived Social Support. Journal of Personality Assessment, 52, 30-41. 